\title{
Short-term effects of nitrogen dioxide on mortality: an analysis within the APHEA project
}

\author{
E. Samoli*, E. Aga\#, G. Touloumi*, K. Nisiotis*, B. Forsberg", A. Lefranc ${ }^{+}$,

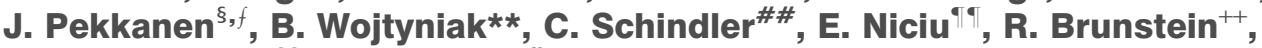 \\ M. Dodič Fikfak ${ }^{\S \S}$, J. Schwartz ${ }^{\#}$ and K. Katsouyanni*
}

ABSTRACT: The short-term effects of nitrogen dioxide $\left(\mathrm{NO}_{2}\right)$ on total, cardiovascular and respiratory mortality in $\mathbf{3 0}$ European cities participating in the Air Pollution on Health: a European Approach (APHEA)-2 project were investigated.

The association was examined using hierarchical models implemented in two stages. In the first stage, data from each city were analysed separately, whereas in the second stage, the cityspecific air pollution estimates were regressed on city-specific covariates to obtain overall estimates and to explore sources of possible heterogeneity.

A significant association of $\mathrm{NO}_{2}$ with total, cardiovascular and respiratory mortality was found, with stronger effects on cause-specific mortality. There was evidence of confounding in respiratory mortality with black smoke and sulphur dioxide. The effect of $\mathrm{NO}_{2}$ on total and cardiovascular mortality was observed mainly in western and southern European cities, and was larger when smoking prevalence was lower and household gas consumption was higher. The effect of $\mathrm{NO}_{2}$ on respiratory mortality was higher in cities with a larger proportion of elderly persons in the population and higher levels of particulate matter with a $50 \%$ cut-off aerodynamic diameter of $10 \mu \mathrm{m}$.

The results of this large study are consistent with an independent effect of nitrogen dioxide on mortality, but the role of nitrogen dioxide as a surrogate of other unmeasured pollutants cannot be completely ruled out.

KEYWORDS: Air pollution, heterogeneity, modelling, mortality, nitrogen dioxide

$\mathbf{M}$ any epidemiological studies have documented adverse short-term effects of different types of air pollution on health outcomes in recent years [1-5]. The pollution indicators used were mainly ambient particles [4, $6,7]$, but gaseous pollutants, such as nitrogen dioxide $\left(\mathrm{NO}_{2}\right)$, ozone $\left(\mathrm{O}_{3}\right)$ and carbon monoxide (CO), have also been shown to have adverse effects on mortality and morbidity [3, 8-10]. The results from epidemiological studies have led to revisions of air quality guidelines and standards and scheduled dates for regular revisions in the future [11-13].

Nitrogen oxides $\left(\mathrm{NO}_{\mathrm{x}}\right)$, primarily nitric oxide (NO), are produced from high-temperature combustion, such as when fuel is burned in motor vehicles and power plants. Once emitted, NO relatively rapidly reacts with $\mathrm{O}_{3}$ or oxygen to form $\mathrm{NO}_{2}$. This usually dominating part is known as secondary $\mathrm{NO}_{2}$, but the transformation mainly takes place close to the source. Primary $\mathrm{NO}_{2}$ emissions are particularly important from diesel vehicles, and this fraction seems to be increasing in Europe. Due to nonlinearities in the oxidation reactions and variations in the background $\mathrm{O}_{3}$ levels, $\mathrm{NO}_{x}$ has a stronger temporal correlation than $\mathrm{NO}_{2}$ has with other combustion products (exhaust particles, $\mathrm{CO}$, sulphur dioxide $\left(\mathrm{SO}_{2}\right)$ ) emitted at the same time from cars and other sources. Indoor air can also be contaminated with high levels of $\mathrm{NO}_{2}$, since unventilated heaters and gas stoves also emit substantial amounts of $\mathrm{NO}_{2}$.

In spite of laboratory, clinical and epidemiological research, the health effects of $\mathrm{NO}_{2}$ exposure on humans are not well understood. The toxicological evidence suggests that increased susceptibility to infection, functional deficits from effects on airways, and deterioration of the status of persons with chronic respiratory conditions,
AFFILIATIONS

*Dept of Hygiene and Epidemiology University of Athens, Athens, Greece. \#Harvard School of Public Health, Boston, MA, USA.

"Dept of Public Health and Clinical Medicine, Umeå University, Umeå, Sweden.

${ }^{+}$Regional Observatory of Health, llede-France, France.

${ }^{5}$ Dept of Public Health and Clinical Nutrition, University of Kuopio, and ${ }^{f}$ National Public Health Institute, Unit of Environmental Epidemiology, Kuopio, Finland.

${ }^{\star}{ }^{\star}$ National Institute of Hygiene, Dept of Medical Statistics, Population Studies Laboratory, Warsaw, Poland \#\#Institute of Social and Preventive Medicine, University of Basel, Basel, Switzerland.

"Dept of Environmental Health, Institute of Public Health Bucharest, Bucharest, Romania.

${ }^{++}$Center for Quality \& Safety, Hadassah University Hospital, Jerusalem, Israel.

${ }^{\S}$ Institute of Public Health,

Ljubljana, Slovenia.

CORRESPONDENCE

E. Samoli, Dept of Hygiene and Epidemiology, University of Athens Medical School, 75 Mikras Asias Street, 11527 Athens, Greece. Fax: 302107462205 E-mail: esamoli@med.uoa.gr

Received:

December 072005

Accepted after revision:

February 262006

SUPPORT STATEMENT

This work was funded by two grants from the European Commission Environment and Climate Programme (contract numbers ENV4-CT97-0534 and QLK4-CT-2001-30055).

European Respiratory Journal Print ISSN 0903-1936 Online ISSN 1399-3003 
including asthmatics, are of potential concern. $\mathrm{NO}_{2}$ is a highly reactive, nitrogen-centred free radical, poorly water-soluble gas deposited peripherally in the lungs. It is absorbed along the entire respiratory tract, but exposure studies indicate that the major target site for the action of $\mathrm{NO}_{2}$ is the terminal bronchioles. The main mechanism of $\mathrm{NO}_{2}$ toxicity has been suggested to involve lipid peroxidation in cell membranes and various actions of free radicals on structural and functional molecules. Antioxidants such as ascorbic acid and $\alpha$-tocopherol appear to play a protective role [14]. $\mathrm{NO}_{2}$ induces an airway inflammation, probably restricted to the smaller airways and the terminal bronchioles, at least after a single exposure [15]. The main effect of $\mathrm{NO}_{2}$ in human exposure studies has been on bronchial responsiveness, usually seen at concentrations of $\geqslant 1,800 \mu \mathrm{g} \cdot \mathrm{m}^{-3}$ in healthy subjects and $\sim 200-500 \mu \mathrm{g} \cdot \mathrm{m}^{-3}$ in patients with asthma [16] or chronic obstructive pulmonary disease (COPD) [17]. $\mathrm{NO}_{2}$ also has an amplifying effect on the asthmatic response to allergen exposure. A short (15-30 min) exposure to $500 \mu \mathrm{g} \cdot \mathrm{m}^{-3}$ seems to increase the reaction. Some data suggest that exposure to $\mathrm{NO}_{2}$ at concentrations occurring in highly trafficked areas $\left(15 \mathrm{~min}\right.$ at $\left.500 \mu \mathrm{g} \cdot \mathrm{m}^{-3}\right)$ can enhance allergic inflammatory reaction in the airways without causing symptoms or pulmonary dysfunction [18].

Most epidemiological studies on the health effects of $\mathrm{NO}_{2}$ have focused on morbidity rather than mortality. The short-term effects of $\mathrm{NO}_{2}$ on mortality within the Air Pollution and Health: A European Approach (APHEA)-2 project, which uses an extensive European database from 30 European cities, were investigated. Special attention was paid to efforts to distinguish the effects of $\mathrm{NO}_{2}$ per se from confounding or modifying effects of other pollutants, such as particles.

\section{DATA}

APHEA-2 is a multicentre project including 30 cities across Europe and associated regions, which studies short-term health effects of air pollution. Data were collected on daily counts of all-cause mortality, excluding deaths from external causes (International Classification of Disease (ICD)-9: >800), cardiovascular mortality (ICD-9: 390-459) and respiratory mortality (ICD-9: 460-519). The data covered at $\geqslant 3$ consecutive years for each city within the years 1990-1997. In all, $2,893,430$ deaths occurred in the cities studied during that period. Details of the data have been published elsewhere [5].

Daily air pollution measurements were provided by the monitoring networks established in each town participating in the APHEA-2 project [5]. Time series data on daily temperature $\left({ }^{\circ} \mathrm{C}\right.$, daily mean) and relative humidity (\%) were used to control for the potential confounding effects of weather. External information on influenza epidemics or other unusual events (heat waves, strikes, etc.) was also collected, if available [5].

Table 1 presents descriptive characteristics of the data. The total population exposed is $>60$ million. The Netherlands is considered as one urban area because of its relatively small size and dense population. The mean daily total number of deaths ranged from six to 342 . For respiratory mortality, daily counts ranged $<1-29$. The mean levels of $\mathrm{NO}_{2}$ ( $1 \mathrm{~h}$ max) ranged $46-155 \mu \mathrm{g} \cdot \mathrm{m}^{-3}$. In the various cities, the correlation between $\mathrm{NO}_{2}$ and particulate matter with a 50\% cut-off aerodynamic diameter of $10 \mu \mathrm{m}$ (PM10) ranged 0.11-0.69, between $\mathrm{NO}_{2}$ and black smoke (BS) it ranged 0.11-0.78, between $\mathrm{NO}_{2}$ and $\mathrm{SO}_{2} 0.15-0.87$, and between $\mathrm{NO}_{2}$ and $\mathrm{O}_{3}$ $-0.21-0.31$.

For the four Polish cities included in the analysis (i.e. Cracow, Poznan, Lodz, Wroclaw), only $\mathrm{NO}_{2}$ cumulative 24-h measurements were available. In order to include them in the analysis, the maximum hourly $\mathrm{NO}_{2}$ concentration of each day $\left(\mathrm{NO}_{2} 1-\mathrm{h}\right.$ values) was estimated as 1.64 times the 24 -h values, where 1.64 is the average of the ratio between the two measurements in the cities that provided both. There was a substantial variability among all cities in the study of the levels of all pollutants, as well as in the mean daily temperature and humidity.

\section{METHODS}

Within the APHEA-2 project the maximum hourly $\mathrm{NO}_{2}$ concentration of each day $\left(\mathrm{NO}_{2} 1-\mathrm{h}\right)$ was analysed rather than the average concentration of $\mathrm{NO}_{2}$ over $24 \mathrm{~h}\left(\mathrm{NO}_{2} 24-\mathrm{h}\right)$, since more cities provided measurements for the former. The maximum daily 1- and 24-h $\mathrm{NO}_{2}$ concentrations are highly correlated (the correlation coefficient ranges $0.80-0.94$, with a median of 0.90$)$. In the present study, it was decided a priori to use the average of lags 0 and 1 for $\mathrm{NO}_{2}$ for all cities, since there is evidence that the average of 2 days' pollution correlates better with mortality than a single day's exposure [19]. Furthermore, this approach avoids potential bias that could result from selectively reporting the most significant lags. In this analysis, a linear dose-response relationship between $\mathrm{NO}_{2}$ $1-\mathrm{h}$ and mortality was assumed. This assumption was based on previously published results from the APHEA-2 project indicating that the dose-response relationship could be adequately approximated by a linear association (E. Samoli; personal communication) [20]. To investigate the effect of $\mathrm{NO}_{2}$ over a larger number of days and examine the shape of the association with each analysed health outcome, polynomial distributed lag models for the $\mathrm{NO}_{2}$ were fitted, using lags 0 to 5 [19].

For the analysis, a hierarchical modelling approach was used. First, regression models in each city were fitted separately to allow specific control for seasonal effects, weather and other potential confounders. The individual city results were then used in a second-stage analysis to obtain overall estimates and to investigate potential effect modifiers.

\section{Individual city analysis}

The pollution-mortality associations for each city were investigated using Poisson regression models allowing for overdispersion [21]. Smooth functions were used to control for potential confounding effects of seasonality, long-term trends and meteorological variables (mean daily temperature and mean daily relative humidity). A linear term for the pollutant was introduced in the model. The penalised regression splines were used as smoothing functions, as implemented by WOOD [22]. Dummy variables were also included for the day-of-theweek effect, holidays and influenza epidemics.

The general methodological guidelines developed within the framework of the APHEA-2 project were followed, and are described in detail elsewhere [21]. One additional feature is the 
TABLE 1 City descriptive data on the study period, population, exposure (nitrogen dioxide $\left(\mathrm{NO}_{2}\right)$ ) and outcome (daily number of deaths)

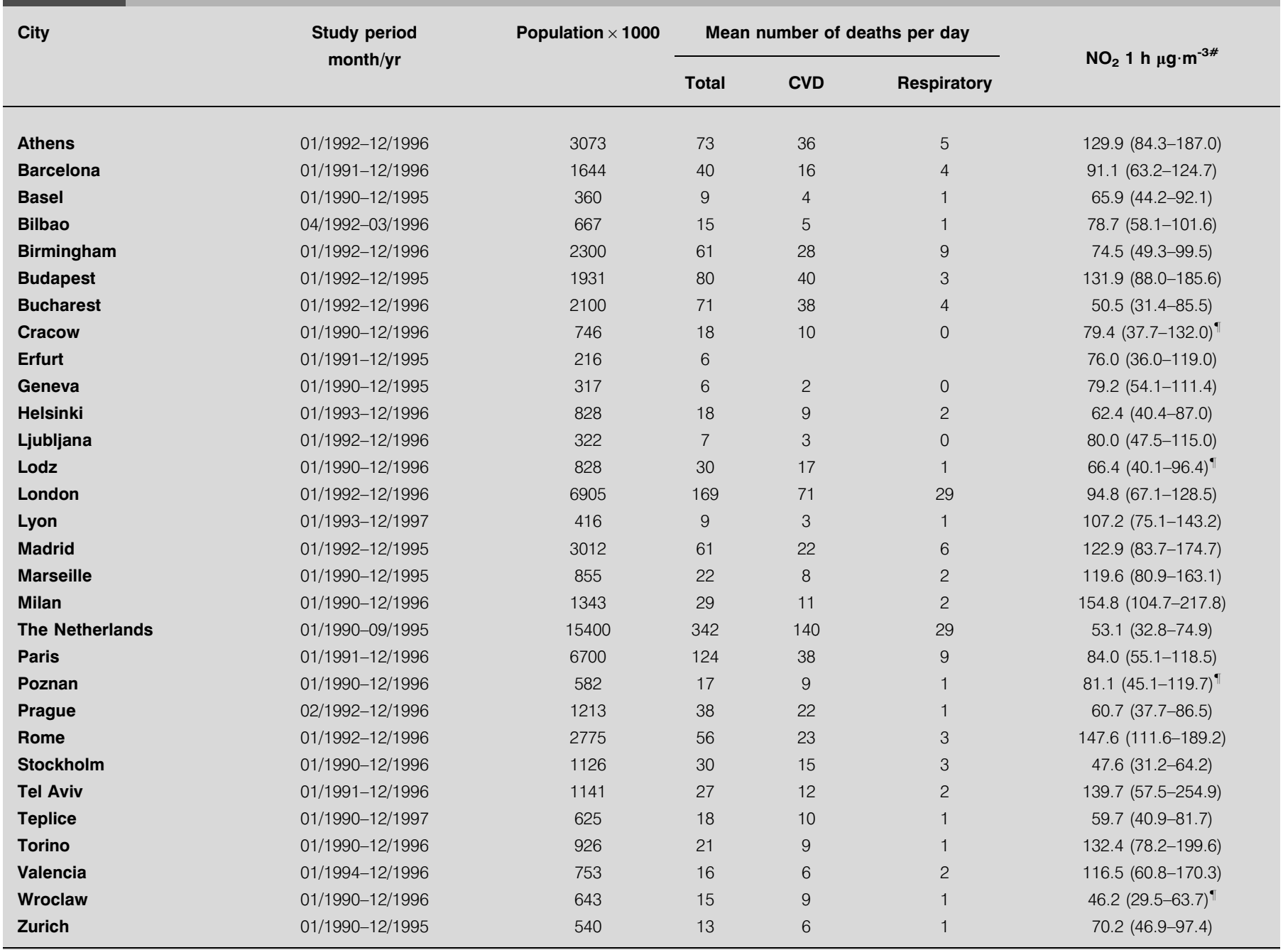

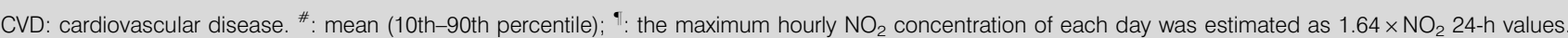

use of penalised regression splines instead of the nonparametric function locally weighted nonparametric smoothers (loess) as smoothing functions to control for possible confounding. The smooth functions of time serve as a proxy for any time-dependent outcome predictors or confounders with long-term trends and seasonal patterns not explicitly included in the model. Hence long-term trends and seasonal patterns were removed from the data to guard against this confounding by omitted variables. Weather variables, which are potential confounders, were included explicitly. In particular, same-day temperature and humidity, and lagged values of these meteorological variables were included in the models. Thinplate regression splines were used as basis functions for the penalised regression splines [23]. Based on experiences from the previous analyses of the APHEA-2 data, the number of basis functions was chosen to be 40 for the time variable and 10 for the weather variables. The smoothing parameters that minimised the absolute value of the sum of partial autocorrelations (PACs) of the residuals from lags 3 to 30 were then chosen. To account for serial correlation in the residuals where it remained in the final model, autoregressive terms were added into the model as appropriate [24]. In the special case of the small cities (and especially in cause-specific mortality), a minimum of one degree of freedom per year was required.

The APHEA-2 method was used for influenza control, including a dummy variable taking the value of one when the 7-day moving average of the respiratory mortality was greater than the 90th percentile of its city-specific distribution. Since the influenza control, as described, was based on the distribution of respiratory mortality, the influenza dummy variable was included only when the total and cardiovascular mortality were analysed [21]. Based on previously published results $[25,26]$, there is no indication that omitting control for influenza when respiratory mortality was analysed would influence the association between air pollution and mortality. It is unclear why the specific time within a winter that an epidemic occurs in a particular city should have much to do with air pollution levels and hence confound the relation under investigation. Nevertheless, to further explore the 
potential confounding effects of influenza on respiratory mortality, respiratory mortality was also analysed for days below the 90th percentile of its distribution.

To evaluate how sensitive the present results are to the choice of the degree of smoothing, models with $\pm 25 \%$ of the degrees of freedom for the time smoothing that were chosen based on the PAC criterion were also applied.

To investigate potential confounding effects of the daily levels of other pollutants, two pollutant models were also applied, i.e. $\mathrm{NO}_{2}$ and alternatively PM10 (24-h mean), $\mathrm{SO}_{2}$ (24-h mean) or $\mathrm{O}_{3}$ (maximum of 8-h means) were included in the model, and were also applied.

Some studies have demonstrated that the effects of air pollution on mortality are spread over $>2$ days $[19,27]$. To examine this question, a separate distributed lag model was fitted for each city. A cubic polynomial distributed lag with lags to 5 days before the deaths was used, which has proven adequate in past studies [19]. Therefore, the coefficients for the cubic polynomial that define the shape of the distributed lag were estimated in each city.

\section{Second-stage analysis}

It was assumed that the city-specific effect estimates (for the mean of lags 0 and 1) to be normally distributed around an overall estimate. Fixed effects, pooled, regression coefficients by weighted regression of city-specific estimates on potential effect modifiers (at city level), with weights inversely proportional to their city-specific variances, were estimated. If substantial heterogeneity remained among city results beyond the variation explained by the effect modifiers, random-effects regression models were applied. In these models, it was assumed that the true city-specific coefficients are a sample of independent observations from the normal distribution with means equal to the random effects, pooled estimate and variance equal to the between-cities variance. The random variance component was estimated using the method of moments [28]. In order to combine the city-specific coefficients from the polynomial distributed lags models, the multivariate maximum likelihood method was used [29].

\section{RESULTS}

Table 2 shows the percentage increase in the daily number of deaths associated with $10 \mu \mathrm{g} \cdot \mathrm{m}^{-3}$ increase in $\mathrm{NO}_{2}$ levels, as well as the corresponding figures adjusting for seasonality using $\pm 25 \%$ of the number of degrees of freedom determined by the PAC criterion. Because there was significant heterogeneity in the single-city results, pooled estimates using random effects models are also shown. For $10 \mu \mathrm{g} \cdot \mathrm{m}^{-3}$ increase in the daily $\mathrm{NO}_{2}$ concentrations, the increase in total deaths was $0.30 \%$ (95\% confidence intervals (CIs): $0.22-0.38 \%$ ), for cardiovascular mortality the associated increase was $0.40 \%$ $(0.29-0.52 \%)$ and for respiratory mortality $0.38 \%(0.17-0.58 \%)$. When adjusted for seasonality using more degrees of freedom, the associated effect in all studied outcomes decreased by $<13 \%$ compared with the baseline model. When adjusted for seasonality using fewer degrees of freedom, the associated effect in all studied outcomes increased by $<16 \%$. When respiratory mortality restricted to days below the 90th percentile of its distribution was analysed, the pooled effect was slightly increased (associated estimate $0.41 \% \quad(0.25-$ $0.58 \%)$ ), supporting the hypothesis of absence of confounding by influenza epidemics.

Figure 1 shows the increase in total mortality and its 95\% CIs associated with an increase of $10 \mu \mathrm{g} \cdot \mathrm{m}^{-3}$ in the levels of $\mathrm{NO}_{2}$ using the average of 0,1 (black lines) or polynomial distributed lag models for lags $0-5$ (red lines) for each city included in the analysis as well as the combined results. Distributed lag models in Bucharest were not applied because of systematically missing exposure data. Statistically significant results for single cities ranged from $0.20 \%$ in Madrid to $1.14 \%$ in Wroclaw for the baseline model, and from $0.32 \%$ in Paris to $1.30 \%$ in Wroclaw for the distributed lags model. The overall increase in total mortality from the distributed lags model was higher by $23 \%$ compared with the effect from the baseline model.

Figure 2 shows the per-city and combined increases in cardiovascular mortality and the $95 \%$ CIs associated with an increase of $10 \mu \mathrm{g} \cdot \mathrm{m}^{-3}$ in the levels of $\mathrm{NO}_{2}$, when either two (black lines) or six (red lines) days of exposure were analysed. Statistically significant results for single cities ranged from $0.33 \%$ in Tel Aviv to $1.58 \%$ in Wroclaw for the baseline model, and from $0.58 \%$ in the Netherlands to $1.97 \%$ in Wroclaw for the distributed lags model. The overall increase in cardiovascular mortality from the distributed lags model was higher by $22 \%$ compared with the effect from the baseline model.

Figure 3 shows the per city and combined increases in respiratory mortality and the $95 \%$ CIs associated with an increase of $10 \mu \mathrm{g} \cdot \mathrm{m}^{-3}$ in the levels of $\mathrm{NO}_{2}$, when either 2 (black lines) or 6 days (red lines) of exposure were analysed. Statistically significant results for single cities ranged from $0.92 \%$ in Torino to $2.88 \%$ in Ljubljana for the baseline model, and from $0.98 \%$ in Milan to $5.25 \%$ in Geneva for the distributed

\begin{tabular}{|c|c|c|c|}
\hline \multirow[t]{3}{*}{ TABLE 2} & \multicolumn{3}{|c|}{$\begin{array}{l}\text { Pooled estimates for the increase in mortality } \\
\text { associated with an increase of } 10 \mu \mathrm{g} \cdot \mathrm{m}^{-3} \text { in } \\
\text { nitrogen dioxide }\left(\mathrm{NO}_{2} ; \text { average of lags } 0 \text { and } 1 \text { of }\right. \\
\left.\text { the } 1-\mathrm{h} \text { maxima of } \mathrm{NO}_{2}\right) \text { for different choices of } \\
\text { the number of degrees of freedom used for } \\
\text { seasonality control }\end{array}$} \\
\hline & \multicolumn{3}{|c|}{ Model } \\
\hline & $\begin{array}{l}\text { Degrees of } \\
\text { freedom }\end{array}$ & Fixed effects & $\begin{array}{c}\text { Random } \\
\text { effects }\end{array}$ \\
\hline \multirow[t]{3}{*}{ Total mortality } & $-25 \%$ & $0.34(0.29-0.39)$ & $0.33(0.24-0.42)$ \\
\hline & Baseline mode & $0.30(0.25-0.35)$ & $0.30(0.22-0.38)$ \\
\hline & $+25 \%$ & $0.27(0.22-0.32)$ & $0.27(0.19-0.36)$ \\
\hline \multirow[t]{3}{*}{ CVD mortality } & $-25 \%$ & $0.45(0.37-0.52)$ & $0.43(0.32-0.55)$ \\
\hline & Baseline model ${ }^{\#}$ & $0.41(0.34-0.49)$ & $0.40(0.29-0.52)$ \\
\hline & $+25 \%$ & $0.37(0.30-0.45)$ & $0.37(0.25,0.49)$ \\
\hline \multirow{3}{*}{$\begin{array}{c}\text { Respiratory } \\
\text { mortality }\end{array}$} & $-25 \%$ & $0.40(0.23-0.57)$ & $0.44(0.24-0.65)$ \\
\hline & Baseline model ${ }^{\#}$ & $0.34(0.17-0.51)$ & $0.38(0.17-0.58)$ \\
\hline & $+25 \%$ & $0.31(0.13-0.48)$ & $0.33(0.13-0.52)$ \\
\hline
\end{tabular}




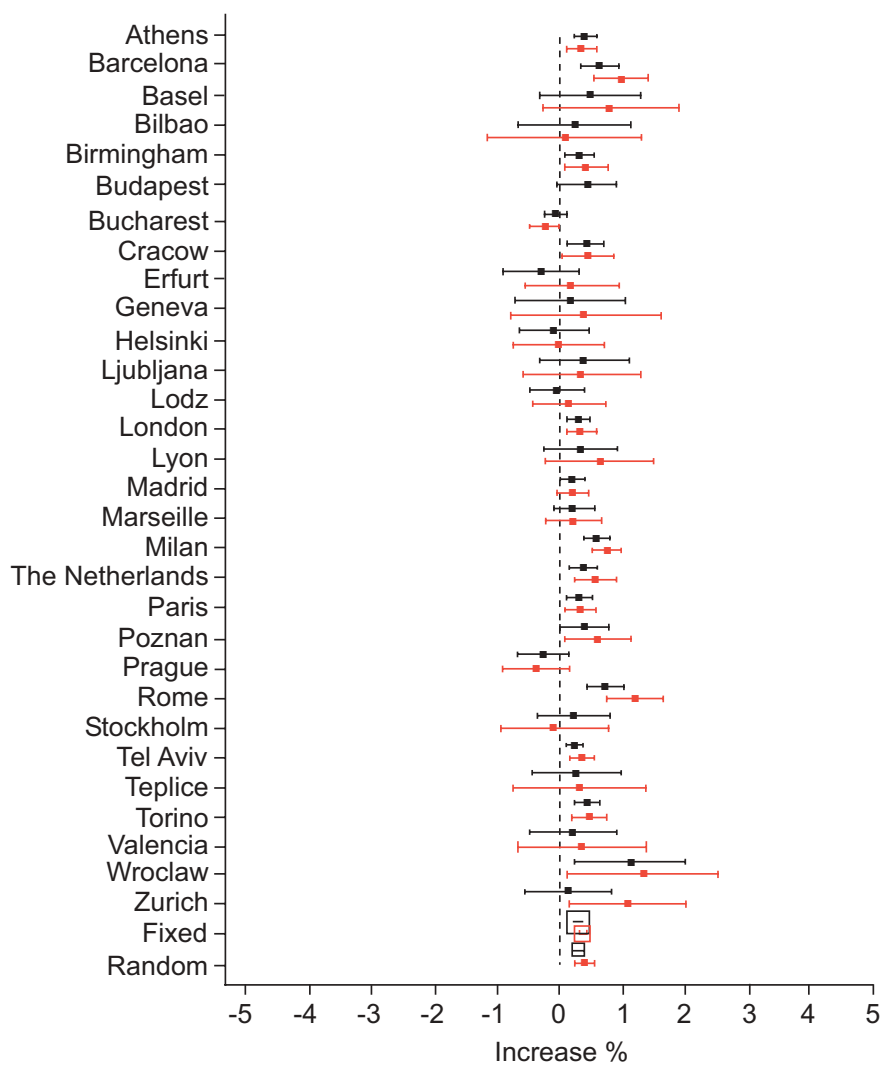

FIGURE 1. Percentage increase in total mortality and its $95 \%$ confidence intervals associated with an increase of $10 \mu \mathrm{g} \cdot \mathrm{m}^{-3}$ in the levels of nitrogen dioxide, using the average of lags $0-1$ (black line) or polynomial distributed lags models for lags 0-5 (red line). The boxes represent the inverse of the squared SE. Fixed: fixed pooled estimate; Random: random pooled estimate.

lags model. The overall increase in respiratory mortality from the distributed lags model was higher by $45 \%$ compared with the effect from the baseline model.

Figure 4 presents the shape of the association of total and respiratory mortality with $\mathrm{NO}_{2}$ over 6 days (lags 0 to 5 ) combined for all cities using a cubic polynomial distributed lag model. The shape of association with cardiovascular mortality is not displayed since it was analogous to the one observed for total mortality. In the case of total mortality, the highest effects are observed in lags 1 and 2. From there on, there is a decrease in the effect, but in the final lag 5 , the effect of the pollutant on mortality appears to increase again. This S-shape is not so apparent in the case of respiratory mortality where the effect of $\mathrm{NO}_{2}$ seems to persist over more days, and this pattern is reflected in the higher size of the cumulative exposure effect compared with 0-1 lags seen for this outcome.

Table 3 presents results from two pollutant models, adjusting in turn for the confounding effects of $\mathrm{BS}, \mathrm{PM} 10, \mathrm{SO}_{2}$ and $\mathrm{O}_{3}$. $\mathrm{NO}_{2}$ associations with total and cardiovascular mortality are not confounded by any of these pollutants. The association with respiratory mortality was substantially confounded by $\mathrm{BS}$, and more so by $\mathrm{SO}_{2}$ levels. When adjusting for $\mathrm{BS}$, the estimated increase in respiratory mortality associated with an increase of $10 \mu \mathrm{g} \cdot \mathrm{m}^{-3}$ in the levels of $\mathrm{NO}_{2}$ was reduced by $32 \%$,

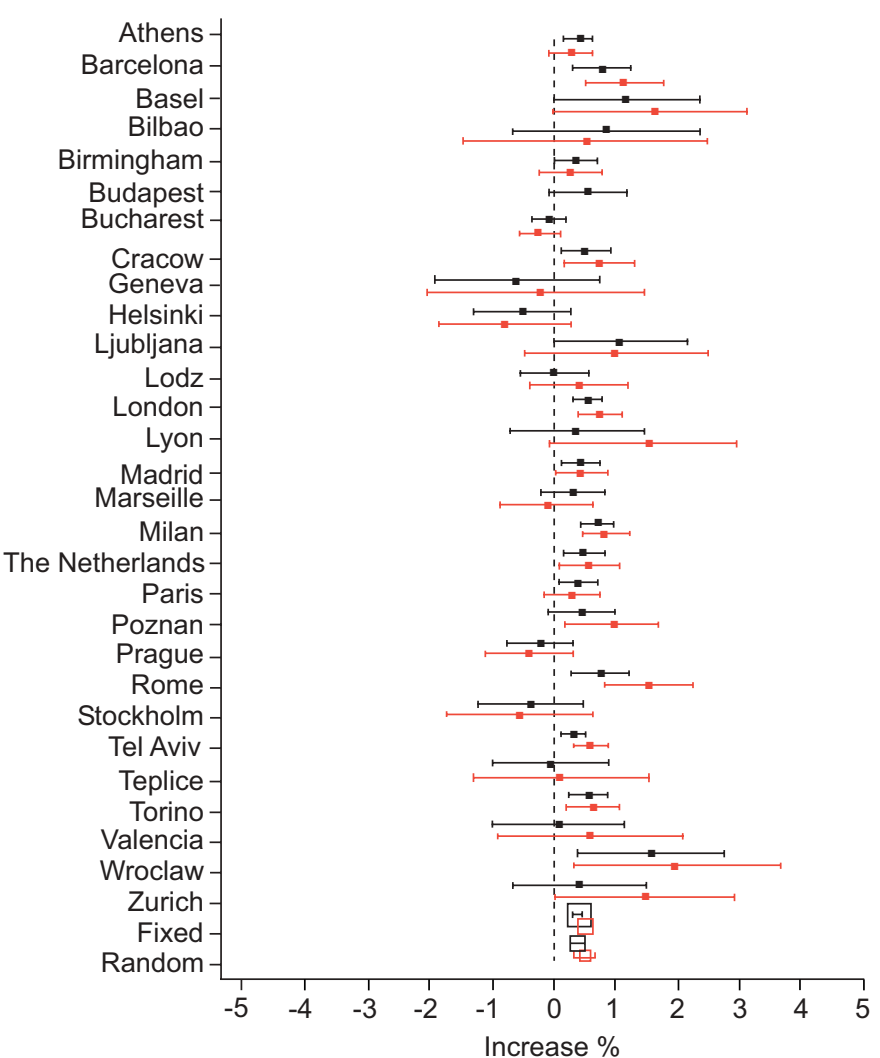

FIGURE 2. Percentage increase in cardiovascular mortality and its $95 \%$ confidence intervals associated with an increase of $10 \mu \mathrm{g} \cdot \mathrm{m}^{-3}$ in the levels of nitrogen dioxide, using the average of lags $0-1$ (black lines) or polynomial distributed lags models for lags $0-5$ (red lines). The boxes represent the inverse of the squared SE. Fixed: fixed pooled estimate; Random: random pooled estimate.

and it even decreased by $50 \%$ and became nonsignificant when adjusting for $\mathrm{SO}_{2}$.

The observed heterogeneity in the effect estimates of $\mathrm{NO}_{2}$ was examined using potential-effect modifiers in second-stage regression models. Potential-effect modifiers used in the APHEA-2 analysis included variables describing the air pollution level and mix in each city, the health status of the population, the geographical area and the climatic conditions [5]. Table 4 shows the resulting estimated $\mathrm{NO}_{2}$ effect (that is, the increase in mortality and its $95 \%$ CIs per $10 \mu \mathrm{g} \cdot \mathrm{m}^{-3}$ increase in the daily levels of $\mathrm{NO}_{2}$ ) for two cities characterised by a value of the effect modifier equal to the first and the third quartile of the respective distribution. Among the potential effect modifiers, only those explaining $>10 \%$ of the heterogeneity are presented.

When investigating the source of heterogeneity in the association between $\mathrm{NO}_{2}$ and total and cardiovascular mortality, the most important effect modifier was the geographical area (defined as western, southern and central eastern European cities), followed by the prevalence of smoking in the city. More specifically, in cities with a lower prevalence of smoking the effect of $\mathrm{NO}_{2}$ on total and cardiovascular mortality was greater. The highest effect of $\mathrm{NO}_{2}$ on total and cardiovascular disease mortality was in north-western cities, followed closely 


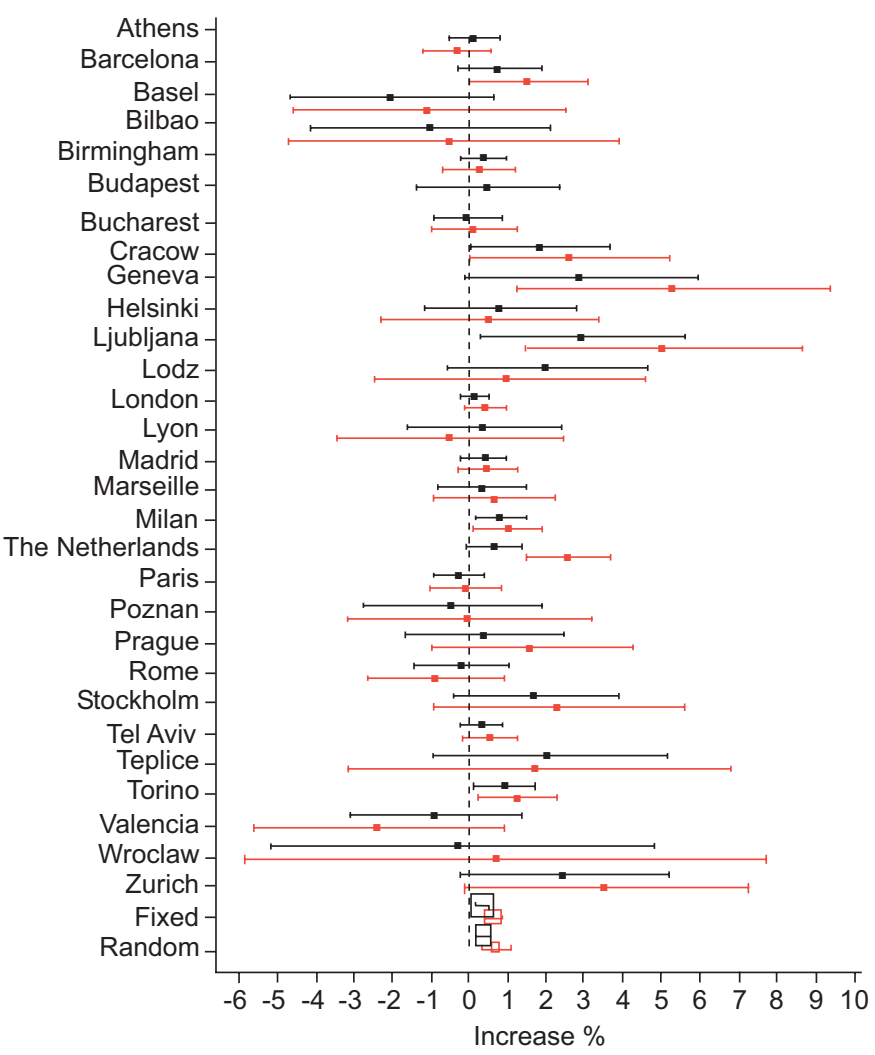

FIGURE 3. Percentage increase in respiratory mortality and its $95 \%$ confidence intervals associated with an increase of $10 \mu \mathrm{g} \cdot \mathrm{m}^{-3}$ in the levels of nitrogen dioxide, using the average of lags $0-1$ (black line) or polynomial distributed lags models for lags $0-5$ (red line). The boxes represent the inverse of the squared SE. Fixed: fixed pooled estimate; Random: random pooled estimate.

by the effect in southern European cities, while there was only a small and nonsignificant effect in eastern cities. Concerning cardiovascular mortality, there was additional evidence that household consumption of natural gas acted as an effect modifier, with higher $\mathrm{NO}_{2}$ effect where the consumption was higher. Finally, in the association with respiratory mortality the most important effect modifiers were the median levels of PM10 followed by the proportion of the elderly (i.e. $>65$ yrs of age) in the population of the city. In cities with high median PM10 levels and a high proportion of elderly people, there was a stronger effect of $\mathrm{NO}_{2}$ on respiratory mortality.

\section{DISCUSSION}

In studies published during the recent decades, $\mathrm{NO}_{2}$ has been associated with a decrease in lung function, an increase in respiratory symptoms and an increase in asthma and COPD hospital admissions. Most of the epidemiological studies of short-term effects of $\mathrm{NO}_{2}$ on health were focused on symptoms reported in diaries, on hospitalisation for respiratory diseases, and on decrease of pulmonary function [30-33]. A few studies have been conducted on the effects of photochemical air pollution on mortality [34-37]. The most extensive European database available today to investigate the potential effects of $\mathrm{NO}_{2}$ on mortality was used.
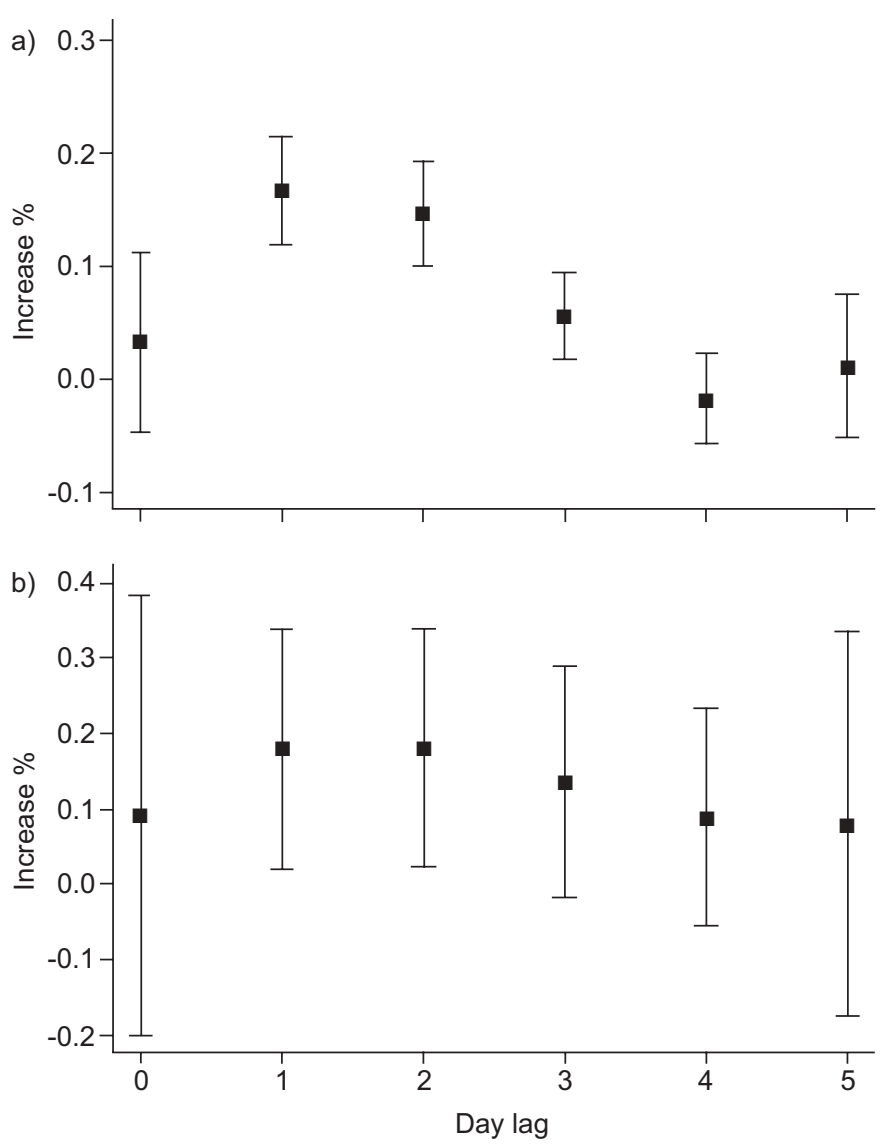

FIGURE 4. Shape of the association of a) total and b) respiratory mortality with nitrogen dioxide over 6 days (lags $0-5$ ) summarised over all cities using a cubic polynomial distributed lag model.

Significant adverse health effects of $\mathrm{NO}_{2}$ on total, cardiovascular and respiratory mortality, with stronger effects on cause-specific mortality have been found. These findings complement those previously reported from APHEA-1, which was the first part of the APHEA project and included a smaller number of cites (i.e. only six compared with 30 cities included in the APHEA-2 analysis). As part of that analysis, TOULOUMI et al. [3] have reported significant positive associations between $\mathrm{NO}_{2}$ and daily total deaths. In that first part of the APHEA analysis, an increase per $10 \mu \mathrm{g} \cdot \mathrm{m}^{-3}$ in $\mathrm{NO}_{2}$ was associated with $0.26 \%$ increase in total mortality compared with $0.30 \%$ increase reported in the present results. KINNEY and OZKAYNAK [34] also found a significant association of $\mathrm{NO}_{2}$ with total and cardiovascular mortality in Los Angeles County, USA. However, no significant association was observed for respiratory deaths. The authors suggested that the small number of deaths from respiratory causes may have limited the power to detect small pollution effects. In the present analysis, where power is gained by use of multiple locations, there is a stronger effect on respiratory mortality compared with total mortality. However, the associated standard error is larger and the effect decreases and becomes nonsignificant when controlling for BS and $\mathrm{SO}_{2}$. Finally, in the analysis of 20 US cities within the National Morbidity, Mortality, and Air Pollution Study (NMMAPS) project, no consistent pattern of association between total mortality and $\mathrm{NO}_{2}$ was found [38]. The 
TABLE 3 Pooled estimates for the increase in mortality associated with an increase of $10 \mu \mathrm{g} \cdot \mathrm{m}^{-3}$ in nitrogen dioxide $\left(\mathrm{NO}_{2}\right.$; average of lags 0 and 1 of the 1 -h maxima of $\mathrm{NO}_{2}$ ), adjusting alternatively for the other pollutants (average of lags 0 and 1 )

\begin{tabular}{|c|c|c|c|c|c|c|}
\hline \multirow[t]{2}{*}{ Other pollutant } & \multicolumn{2}{|c|}{ Total mortality } & \multicolumn{2}{|c|}{ CVD mortality } & \multicolumn{2}{|c|}{ Respiratory mortality } \\
\hline & Fixed effects & Random effects & Fixed effects & Random effects & Fixed effects & Random effects \\
\hline BS & $0.33(0.23-0.42)$ & $0.33(0.23-0.42)$ & $0.44(0.31-0.58)$ & $0.44(0.31-0.58)$ & $0.28(-0.02-0.58)$ & $0.26(-0.12-0.65)$ \\
\hline PM10 & $0.27(0.20-0.34)$ & $0.27(0.16-0.38)$ & $0.35(0.24-0.45)$ & $0.35(0.21-0.50)$ & $0.37(0.13-0.61)$ & $0.37(0.08-0.67)$ \\
\hline
\end{tabular}

Data are presented as \% increase (95\% confidence interval). CVD: cardiovascular disease; BS: black smoke; PM10: particle matter with a 50\% cut-off aerodynamic diameter of $10 \mu \mathrm{m} ; \mathrm{SO}_{2}$ : sulphur dioxide; $\mathrm{O}_{3} 8$-h: maximum daily 8-h $\mathrm{O}_{3}$ concentration.

investigators found a positive, but not statistically significant, effect of $\mathrm{NO}_{2}$ at lag 0 and at lag 1 , and a highly statistically significant result at lag 2 . The difference between the NMMAPS and APHEA findings may be attributed to the varying air pollution sources and mixture in Europe and the US.

In this study, the cumulative effect over 6 days was larger by about $22 \%$ for total and cardiovascular mortality and by $45 \%$ for respiratory mortality compared with the average exposure over 2 days. This indicates that previous estimates of $\mathrm{NO}_{2}$ effects may in fact represent an underestimation if they take into account only very short-term health effects. Moreover, when the shape of the association between mortality and $\mathrm{NO}_{2}$ is considered, two different patterns can be distinguished: total and cardiovascular mortality is clearly more affected by $\mathrm{NO}_{2}$ levels on the 2 previous days, whereas for respiratory mortality the effects are more evenly distributed over the 6 previous days. This difference may be explained by differences in the biological mechanisms underlying the health effects of $\mathrm{NO}_{2}$.
Although the above results indicate adverse effects of $\mathrm{NO}_{2}$ on mortality, the independence of its effect from those of other pollutants is still unclear. A single pollutant could act as a marker of a pollution mixture. Hence, $\mathrm{NO}_{2}$ could be a marker of other pollutants generated by vehicle exhausts such as particles. An attempt has been made to estimate the independent effects of pollutants using two pollutant models, for those pollutants for which data were available. No evidence of confounding for total and cardiovascular mortality has been found. There was evidence of confounding by $\mathrm{BS}$ and $\mathrm{SO}_{2}$ in the effect on respiratory mortality. A possible explanation is that the BS- and $\mathrm{SO}_{2}$-adjusted effect estimates of $\mathrm{NO}_{2}$ on respiratory mortality may reflect, to a larger extent, the effects from sources other than traffic. BS is more specific for trafficrelated particles than PM10 and provides a means of addressing the question of particle composition. It was impossible to control for indices for which no measurements were available, for example, the number of particles. Further study focusing on exposure to mixtures including $\mathrm{NO}_{2}, \mathrm{BS}$ and $\mathrm{SO}_{2}$ is needed to further understanding of the aetiological mechanism

TABLE 4 Results of second-stage regression models, investigating the role of potential modifiers ${ }^{\#}$ of the estimated effects ${ }^{\bullet}$ of nitrogen dioxide $\left(\mathrm{NO}_{2}\right.$; average of lags 0 and 1 of the 1-h maxima of $\left.\mathrm{NO}_{2}\right)$ on mortality

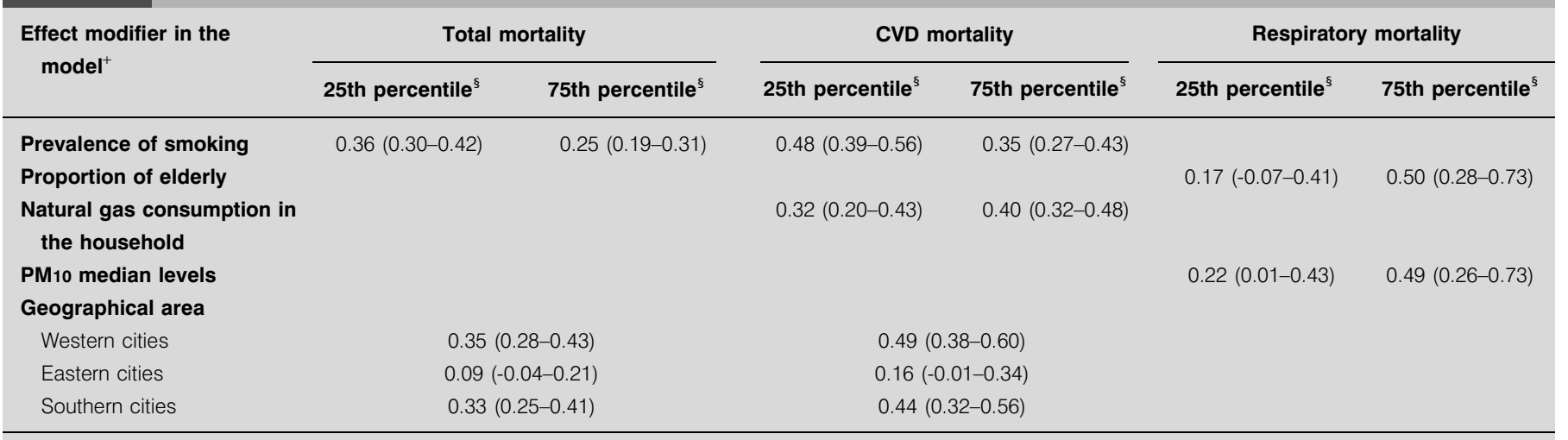

Data are presented as \% increase (95\% confidence interval). CVD: cardiovascular disease; PM10: particulate matter with a $50 \%$ cut-off aerodynamic diameter of $10 \mu \mathrm{m} .{ }^{\#}$ Potential modifiers are variables characterising each city. Only effect modifiers reducing the heterogeneity by $>10 \%$ are presented. ": Effect estimates used from firststage models, are based on the chosen number of degrees of freedom. ${ }^{+}$: The effect modifiers were included alternatively in the model. ${ }^{\varsigma}$ : Estimated increase at the 25 th and 75 th percentiles. Increase in mortality per $10 \mu \mathrm{g} \cdot \mathrm{m}^{-3}$ increase in the daily $\mathrm{NO}_{2}$ concentration, estimated using the fixed-effects model, for a city whose level of the corresponding effect modifier equals to the 25 th and the 75 th percentile, respectively, of the distribution of this effect modifier. 
through which the pollutants affect mortality and, in particular, respiratory mortality.

In order to further investigate the independence of the $\mathrm{NO}_{2}$ effects and contribute to the ongoing discussion on the possible confounding effect of smaller particle sizes, the PM2.5 median level for nine of the analysed cities as potential effect modifier has been used [39]. The PM2.5 median level did not act as significant effect modifier and reduced the heterogeneity by $<10 \%$ in each of the studied outcomes. Besides, if $\mathrm{NO}_{2}$ truly reflects PM2.5, then in cities with a higher PM2.5/PM10 ratio, a higher $\mathrm{NO}_{2} / \mathrm{PM} 10$ level would be expected. This scenario was not verified in four cities with relevant data (Athens, Birmingham, Helsinki, Amsterdam; the Relationship between Ultrafine and fine Particulate matter in Indoor and Outdoor air and respiratory Health (RUPIOH) project, unpublished data). Finally, the correlation between PM10 and PM2.5 in these four cities ranged 0.58-0.95. These high correlations indicate that controlling for PM10, as in the two-pollutants analysis, is largely equivalent to controlling for PM2.5. However, the data used in this approach are limited to only a few cities.

SEATON et al. [40] suggest that $\mathrm{NO}_{2}$ is a surrogate for particle numbers. Their hypothesis is illustrated using data only from Aberdeen where the correlation of $\mathrm{NO}_{2}$ with PM10 is 0.45 , with PM2.5, 0.55, and with particle numbers, 0.89. However, this correlation is fairly high. In a recent three-city study [41], the correlation between ultrafine particles and $\mathrm{NO}_{2}$ were $0.49,0.72$ and 0.82 . Therefore, in many cases it is possible to separate the effects of $\mathrm{NO}_{2}$ and ultrafine particles. Using information from four European cities (the RUPIOH project, unpublished data) that provided relevant data for the present analysis, the correlation between $\mathrm{NO}_{2}$ and $\mathrm{PM} 10$ ranged 0.38-0.54, between $\mathrm{NO}_{2}$ and $\mathrm{PM} 2.5,0.43-0.63$, between $\mathrm{NO}_{2}$ and particle numbers, 0.53-0.72, and between PM10 and particle numbers, 0.19-0.54. Hence, in the present data, the associations between $\mathrm{NO}_{2}$ and particle numbers are not so high as to make the distinction of the effects impossible, as in the case of SEATON et al. [40]. It should be noted that among these four cities, the one with the highest $\mathrm{NO}_{2}$ particle numbers correlation (Helsinki) had the lowest estimated $\mathrm{NO}_{2}$ effect on total mortality.

The present authors investigated heterogeneity in the effect estimates between cities by taking into account several city characteristics, and environmental and social factors as potential effect modifiers. It was found that when smoking prevalence is lower, the effect of $\mathrm{NO}_{2}$ on total and cardiovascular mortality is larger. A possible explanation may be that smoking acts as a competing risk, harvesting the population of susceptible individuals, but this issue needs further investigation. Furthermore, the effect of $\mathrm{NO}_{2}$ on total and cardiovascular mortality was observed mainly in western and southern European cities. In more than half of the eastern European cities involved in the analysis, the $\mathrm{NO}_{2}$ 1-h levels were in the lower range of the observed distribution. Domestic gas consumption as an indicator of domestic $\mathrm{NO}_{2}$ exposure acted as potential effect modifier in cardiovascular mortality, indicating that the effect of outdoor $\mathrm{NO}_{2}$ exposure increased with higher indoor exposure. The risk contrast is not so pronounced and it is difficult to believe that indoor pollution levels act as an effect modifier for the association of outdoor $\mathrm{NO}_{2}$ levels and mortality, unless the slope becomes steeper at higher cumulative exposures. Another likely explanation may lie in the association of higher gas consumption in the more developed cities with characteristic air pollution sources (e.g. more traffic). Finally, the effect of $\mathrm{NO}_{2}$ on respiratory mortality was higher in cities with a larger proportion of elderly persons in the population, for whom there is evidence of increased susceptibility to other pollutants. For cities with higher PM10 levels, larger $\mathrm{NO}_{2}$ effects were estimated, which may mean that the two pollutants act synergistically. One limitation of the present study's second-stage analysis is that there is a noticeable difference in the effects between Eastern European and other cities. Hence, any variables, such as the mortality rate, etc. that strongly differ between the two regions are likely to appear as significant explanatory factors of the heterogeneity in the effect estimates. Or alternatively, if the effect modifiers identified are indeed true modifiers, their distribution across Europe may result in these marked geographical differences.

In conclusion, the present results confirm those previously reported concerning the adverse effects of nitrogen dioxide on mortality and complement them by investigating potential confounding by other pollutants and possible effect modification. The results of this large study are consistent with an independent effect of nitrogen dioxide on mortality, but the role of nitrogen dioxide as a surrogate of other unmeasured pollutants cannot be completely ruled out. Since the short-term effects of nitrogen dioxide on respiratory mortality may be confounded by other vehicle-derived pollutants, further investigation is needed to enhance understanding of the underlying biological mechanism.

\section{REFERENCES}

1 Schwartz J, Dockery DW. Increased mortality in Philadelphia associated with daily air pollution concentrations. Am Rev Respir Dis 1992; 145: 600-604.

2 Pope CA, Dockery DW, Schwartz J. Review of epidemiologic evidence of health effects of particulate air pollution. Inhal Toxicol 1995; 7: 1-18.

3 Touloumi G, Katsouyanni K, Zmirou D, et al. Short-term effects of ambient oxidant exposure on mortality: a combined analysis within the APHEA Project. Am J Epidemiol 1997; 146: 177-184.

4 Samet JM, Dominici F, Curriero FC, Coursac I, Zeger SL. Fine particulate air pollution and mortality in 20 U.S. cities, 1987-1994. N Engl J Med 2000; 343: 1742-1749.

5 Katsouyanni K, Touloumi G, Samoli E, et al. Confounding and effect modification in the short-term effects of ambient particles on total mortality: results from 29 European cities within the APHEA2 project. Epidemiology 2001; 12: 521-531.

6 Pope CA III, Dockery DW. Epidemiology of particle effects. In: Holgate ST, Samet JM, Koren HS, eds. Air pollution and Health. San Diego, Academic Press, 1999; pp. 673-705.

7 Katsouyanni K, Touloumi G, Spix C, et al. Short term effects of ambient sulphur dioxide and particulate matter on mortality in 12 European cities: results from time series data from the APHEA project. BMJ 1997; 314: 1658-1663.

8 Schwartz J. Air pollution and hospital admissions for cardiovascular disease in Tuscon. Epidemiology 1997; 8: 371-377. 
9 Gryparis A, Forsberg B, Katsouyanni K, et al. Acute effects of ozone on mortality from the "Air pollution and health: a European approach" Project. Am J Respir Crit Care Med 2004; 170: 1080-1087.

10 Schwartz J. How sensitive is the association between ozone and daily deaths to control for temperature? Am J Respir Crit Care Med 2005; 171: 627-631.

11 World Health Organization. Air Quality Guidelines for Europe. 2nd Edn. WHO Regional Publications European Series No. 91, Copenhagen, Denmark, 2000.

12 US Environmental Protection Agency Office of Air Quality Planning and Standards. Review of the National Ambient Air Quality Standards for Particulate Matter: Policy Assessment of Scientific and Technical Information. WAWPS Staff Paper. EPA-45/R-1996:96-013. Research Triangle Park, NC, US EPA Office of Air Quality Planning and Standards, 1996.

13 Commission of the European Communities. Council Directive 1999/30/EC relating to limit values for sulphur dioxide, oxides of nitrogen, particulate matter and lead in ambient air. Brussels, European Commission, 1999.

14 Kelly FJ, Blomberg A, Frew A, Holgate ST, Sandström T. Antioxidant kinetics in lung lavage fluid following exposure of humans to nitrogen dioxide. Am J Respir Crit Care Med 1996; 154: 1700-1705.

15 Blomberg A, Krishna MT, Bocchino V, et al. The inflammatory effects of 2 ppm $\mathrm{NO}_{2}$ on the airways of healthy subjects. Am Respir Crit Care Med 1997; 156: 418-424.

16 Folinsbee LJ. Does nitrogen dioxide exposure increase airways responsiveness? Toxicol Ind Health 1992; 8: 273-283.

17 Morrow PE, Utell MJ, Bauer MA, et al. Pulmonary performance of elderly normal subjects and subjects with chronic obstructive pulmonary disease exposed to $0.3 \mathrm{ppm}$ nitrogen dioxide. Am Rev Respir Dis 1992; 145: 291-300.

18 Barck C, Lundahl J, Hallden G, Bylin G. Brief exposures to $\mathrm{NO}_{2}$ augment the allergic inflammation in asthmatics. Environ Res 2005; 97: 58-66.

19 Schwartz J. The distributed lag between air pollution and daily deaths. Epidemiology 2000; 11: 320-326.

20 Samoli E, Touloumi G, Zanobetti A, et al. Investigating the dose-response relation between air pollution and total mortality in the APHEA-2 multicity project. Occup Environ Med 2003; 60: 977-982.

21 Touloumi G, Atkinson R, Le Tertre A, et al. Analysis of health outcome time series data in epidemiological studies. Environmetrics 2004; 15: 101-117.

22 Wood SN. Modelling and smoothing parameter estimation with multiple quadratic penalties. J R Statist Soc B 2000; 62: 413-428.

23 Wood SN. Thin plate regression splines. J R Statist Soc B 2003; 65: 95-114.

24 Brumback BA, Ryan LM, Schwartz JD, Neas LM, Stark PC, Burge HA. Transitional regression models, with application to environmental time series. JASA 2000; 95: 16-27.

25 Braga A, Zanobetti A. Do respiratory epidemics confound the association between air pollution and daily deaths? Eur Respir J 2000; 16: 723-726.
26 Touloumi G, Samoli E, Quenel P, et al. Short-term effects of air pollution on total and cardiovascular mortality: the confounding effects of influenza epidemics. Epidemiology 2005; 16: 49-57.

27 Zanobetti A, Schwartz J, Samoli E, et al. The temporal pattern of mortality responses to air pollution: a multicity assessment of mortality displacement. Epidemiology 2002; 13: 87-93.

28 Der Simonian R, Laird N. Meta-analysis in clinical trials. Control Clin Trials 1986; 7: 177-188.

29 Berkey CS, Hoaglin DC, Antczak-Bouckoms A, Mosteller F, Colditz GA. Meta-analysis of multiple outcomes by regression with random-effects. Stat Med 1998; 17: 2537-2550.

30 Pershagen G, Rylander E, Norberg S, Eriksson M, Nordvall SL. Air pollution involving $\mathrm{NO}_{2}$ exposure and wheezing bronchitis in children. Int J Epidemiol 1995; 24: 1147-1153.

31 Pantazopoulou A, Katsouyanni K, Kourea-Kremastinou J, Trichopoulos D. Short-term effects of air pollution on hospital emergency out patient visits and admissions in the Greater Athens, Greece area. Environ Res 1995; 69: 139-144.

32 Ponka A, Virtanen M. Chronic bronchitis, emphysema, and low-level air pollution in Helsinki, 1987-1989. Environ Res 1994; 65: 207-217.

33 Forsberg B, Stjernberg N, Falk M, Lundback B, Wall S. Air pollution levels, meteorological conditions and asthma symptoms. Eur Respir J 1993; 6: 1109-1115.

34 Kinney PL, Ozkaynak H. Associations of daily mortality and air pollution in Los Angeles County. Environ Res 1991; 54: 99-120.

35 Wietlisbach V, Pope CA, Ackermann-Liebrich U. Air pollution and daily mortality in three Swiss urban areas. Soc Prev Med 1996; 41: 107-115.

36 Verhoeff AP, Hoek G, Schwartz J, van Wijnen JH. Air pollution and daily mortality in Amsterdam, the Netherlands. Epidemiology 1996; 7: 225-230.

37 Ostro B, Sanchez JM, Aranda C, Eskeland GS. Air pollution and mortality: results from a study in Santiago, Chile. $J$ Expos Anal Environ Epidemiol 1996; 6: 97-114.

38 Samet JM, Zeger SL, Dominici F, et al. The National Morbidity, Mortality and Air Pollution Study. Part II: Morbidity, Mortality, and Air Pollution in the United States. HEI Research report. Boston, HEI publications, 2000; No. 94, Part II.

39 Sillanpaa M, Frey A, Hillamo R, Salonen RO. Particulate elemental carbon and organic matter during contrasting urban air pollution situations in Europe (PAMCHART). J Aerosol Sci 2004; 35: S1081-S1082.

40 Seaton A, Dennekamp M. Hypothesis: ill health associated with low concentrations of nitrogen dioxide - an effect of ultrafine particles? Thorax 2003; 58: 1012-1015.

41 Ibald-Mulli A, Timonen KL, Peters A, et al. Effects of particulate air pollution on blood pressure and heart rate in subjects with cardiovascular disease: a multicenter approach. Environ Health Perspect 2004; 112: 369-377. 